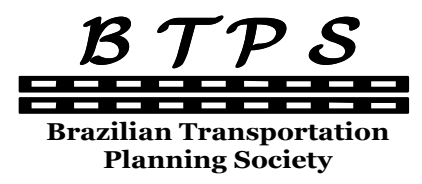

Journal of Transport Literature

Vol. 7, n. 2, pp. 52-77, Apr. 2013

Research Directory

\title{
Mensuração do custo social subjacente à atual frota autônoma de caminhões da agropecuária nacional - um estudo de caso: soja, café e boi em pé
}

[Measuring the social costs underlying the current fleet of trucks autonomous national agriculture

- a case study: soybeans, coffee and live cattle]

\author{
Rodrigo Daniel Caudullo Ronchi, Graziele Araujo Moura*, Carlos Henrique Rocha \\ Universidade de Brasília (UNB), Brazil
}

Submitted 15 Mar 2012; received in revised form 6 Jul 2012; accepted 11 Jul 2012

\begin{abstract}
Resumo
Este trabalho tem por objetivo estimar os custos pagos pela sociedade impostos pela atual frota autônoma de caminhões da agropecuária nacional. Para isto, foram consideradas as seguintes externalidades negativas: poluição ambiental, especialmente, a poluição do ar, e acidentes nas estradas. Somando-se a essas externalidades foi considerado o valor do frete pago pelos usuários dos serviços de transporte como uma pseudoexternalidade. 0 artigo interessa-se por três commodities agrícolas: soja, café em saca e boi em pé. Para o cômputo da externalidade proveniente da poluição ambiental foi utilizado o método dos custos evitados (gastos preventivos). Com relação aos custos sociais dos acidentes nas estradas foram adotados resultados do relatório realizado pelo IPEA (2006). 0 custo relativo ao frete foi calculado pela diferença entre o valor do frete para a frota na idade de 23 anos e o valor do frete para a frota na idade econômica, isto é, pode-se considerar essa diferença como um fator de ineficiência. Enfim, os três custos somados montam, aproximadamente, $\mathrm{R} \$ 27$ mil por caminhão/ano, correspondendo a aproximadamente $15 \%$ do preço de um caminhão novo com tecnologia não-poluidora.
\end{abstract}

Palavras-Chave: frota autônoma de caminhões, mensuração do custo social, idade econômica.

\begin{abstract}
This paper aims to estimate the social costs (negatives externalities) caused by the current Brazilian autonomous fleet of trucks in national agriculture. The emphasis of this study is the measurement of environmental externalities especially, air pollution and road accidents. Also, was considered the freight transportation cost such as fictitious externality. These study focus on three agricultural commodities, soybeans, coffee bags and live cattle. About the externality of environmental pollution was used the method of avoided costs (preventive expenditures). Regarding the social costs of road accidents were adopted results of the report done by IPEA (2006). Considering the three externalities measured, the total annual social cost of externalities underlying the current fleet of trucks autonomous of the national agriculture is at least $\mathrm{R} \$ 27.000$ per truck per year, corresponding to approximately $15 \%$ of the price of a new non-truck polluter with embedded technology.
\end{abstract}

Key words: autonomous fleet of trucks, negatives externalities, economical age.

*Email: grazielemoura@gmail.com.

\section{Recommended Citation}

Ronchi, R. D. C., Moura, G. A. and Rocha, C. H. (2013) Mensuração do custo social subjacente à atual frota autônoma de caminhões da agropecuária nacional - um estudo de caso: soja, café e boi em pé. Journal of Transport Literature, vol. 7, n. 2, pp. 52-77.

- JTL/RELIT is a fully electronic, peer-reviewed, open access, international journal focused on emerging transport markets and published by BPTS - Brazilian Transport Planning Society. Website www.transport-literature.org. ISSN 2238-1031. 


\section{Introdução}

O transporte de cargas é um serviço fundamental na cadeia de produção e distribuição de bens industriais e agrícolas, desempenhando um papel fundamental na logística da produção agropecuária. Conforme o último boletim estatístico publicado em 2010 pela Confederação Nacional do Transporte, CNT, o transporte rodoviário de carga respondeu por $61,1 \%$ do total das cargas movimentadas no país, o que faz do transporte rodoviário um setor de grande importância na atividade econômica do Brasil.

A atual frota brasileira autônoma de caminhões é de cerca de 800 mil veículos, segundo Ronchi (2011). Porém, de acordo com o Registro Nacional dos Transportadores Rodoviários de Carga (ANTT, 2009) somente 669,8 mil veículos estão cadastrados como pertencentes aos transportadores autônomos. Sendo que a maioria dos veículos tem idade igual ou superior a 15 anos; em média têm 23 anos (Rocha, Arruda e Rocha, 2009; Arruda, 2010). A frota é considerada antiga se comparada a de muitos países das Américas e da Europa, observa Arruda (2010).

A idade avançada da frota de caminhões no Brasil gera inúmeros problemas; os caminhões velhos são mais poluidores do que os novos, provocam mais congestionamentos, quebram e exigem mais manutenção, com tendência a elevar o valor do frete cobrado. Os caminhões velhos são mais propícios a causar acidentes, provocando mortes e invalidez, além de danos patrimoniais. Com tecnologia obsoleta, os veículos antigos são menos produtivos e consomem mais combustível do que os novos. Considerando isso, pode-se dizer que os caminhões velhos causam custos extras a sociedade, que passa a dispor de fretes relativamente mais altos.

Enfim, os caminhões velhos impõem externalidades negativas porque poluem a atmosfera e porque provocam acidentes nas estradas e ruas; nesses casos a sociedade tem de arcar com custos de despoluição do ar e custos hospitalares, respectivamente. Para um exame elegante do conceito de externalidade e de suas soluções ver Mata (2010) e Stephen (1993). 
Castro (2008), Rocha, Arruda e Rocha (2009) e Arruda (2010) apresentam formulações teóricas para mensurar as externalidades negativas subjacentes à frota brasileira autônoma de caminhões. Por outra parte, Sandoval, Ronchi e Rocha (2010) avaliam empiricamente os custos externos provocados por essa frota. Cruvinel, Pinto e Granemman (2012) propõe um novo modelo para mensurar a externalidade ambiental provocada pelos caminhões autônomos com idade superior a 30 anos, com foco na redução da emissão de dióxido de carbono.

Assim como Sandoval, Ronchi e Rocha (2010) este artigo estima em termos aproximados os custos sociais subjacentes à atual frota brasileira autônoma de caminhões, com destaque para a frota da agropecuária. A ênfase é na mensuração dos custos externos (a) ambientais, particularmente, a poluição do ar, e (b) com acidentes provocados pelos caminhões. Some-se a esses custos externos(c) o frete cobrado pela frota velha que é maior do que no caso da frota nova.. Contudo, diferentemente do artigo dos autores Sandoval, Ronchi e Rocha (2010), a depreciação do caminhão para avaliar os custos externos ambientais é levada em conta.

E mais, este artigo faz uma contribuição analisando empiricamente as formulações teóricas feitas em trabalhos anteriores, como os de Rocha, Arruda e Rocha (2009), de Arruda (2010) e de Sandoval, Ronchi e Rocha (2010). Destaque deve ser dispensado à formulação para mensurar o custo externo ambiental e às expressões para agregar os custos de impacto ambiental e de valor do frete cobrado.

Faz necessário mencionar que Rocha, Ronchi e Moura (2011) também estimam os custos subjacentes à atual frota autônoma de caminhões, sem destacar uma atividade econômica como a agropecuária. As premissas adotadas pelos autores diferem das assumidas neste artigo, principalmente, no que se refere às distancias médias percorridas pela frota autônoma de caminhão. Cabe mencionar que Cruvinel, Pinto e Granemman (2012) utilizaram método distinto para estimar os custos ambientais produzidos pela frota de caminhões do Brasil. Portanto, os resultados não podem ser motivo de comparação. Mas, de todo modo, tanto este trabalho quanto o de Rocha, Ronchi e Moura (2011) e o de Cruvinel, Pinto e Granemman (2012) demonstram que a renovação da frota consiste em trocar desembolso de custo de capital por um feixe de fluxo de economia em custo social. 


\section{Externalidades: fundamentação teórica}

Nesta seção é apresentada a teoria desenvolvida por Rocha, Ronchi e Moura (2011) para medir o custo social subjacente à atual frota brasileira autônoma de caminhões. $\mathrm{O}$ custo social da frota é medido em termos de poluição atmosférica, acidentes e valor do frete.

Cabe ressaltar que autores como Castro (2008) acrescentam ao custo social total produzido pela frota de caminhões o custo de congestionamento, outros autores incluem os danos provocados ao patrimônio pelos acidentes de trânsito como IPEA (2006).

\subsection{Poluição ambiental (atmosférica)}

Supõe-se que o caminhão novo seja não-poluidor relativamente ao caminhão velho (Meyer, 2001). Posto isso, propõem-se a Equação (1) para medir o custo ambiental subjacente à frota de caminhões:

$$
E_{p}^{k}=P C_{N O V O}^{k}-P C_{V E L H O}^{k}
$$

Onde $E_{p}^{k}$ é externalidade ambiental subjacente ao caminhão $k$ da frota atual; $P C_{N O V O}^{k}$ é o preço do caminhão $k$ novo na época atual e $P C_{V E L H O}^{k}$ é o preço do caminhão $k$ velho, avaliado na época atual

O preço do caminhão velho $k$, avaliado na época atual, é dado por (considera-se a depreciação $\theta)$ :

$$
P C_{V E L H O}^{k}=V F C_{V E L H O}^{k}-\theta \times V F C_{V E L H O}^{k}=(1-\theta) \times V F C_{V E L H O}^{k}
$$

O valor futuro do caminhão velho $V F C_{V E L H O}^{k}$, na Equação (2), é atualizado monetariamente a $\operatorname{taxa} \delta$, assim:

$$
V F C_{V E L H O}^{k}=V A C_{V E L H O}^{k} \times(1+\delta)^{T}
$$

em que $V A C_{V E L H O}^{k}$ : o valor de aquisição do caminhão velho $k$ e $T$ é o tempo (ano); ou seja, é a idade do caminhão velho. 
Se o caminhão apresentar idade maior ou igual a cinco anos $\theta=100 \%$, na Equação (2), caso contrário segue a depreciação de acordo com a Tabela 1.

\section{Tabela 1- Percentual de depreciação de um caminhão ${ }^{1}$}

\begin{tabular}{cc}
\hline Idade/Ano & $\theta$ \\
\hline 1 & $20 \%$ \\
2 & $40 \%$ \\
3 & $60 \%$ \\
4 & $80 \%$
\end{tabular}

Substituindo a Equação (3) em (2), tem-se que o preço do caminhão velho $k$, avaliado na época atual, é função de seu valor de aquisição, dados os parâmetros $\theta$ e $\delta$. Registre-se que as Equações (2) e (3) foram tomadas emprestadas da economia financeira; desconto de títulos financeiros (Bruni e Famá, 2008).

Em suma, a Equação (1) diz que o custo ambiental subjacente a frota de caminhões é medido pela diferença entre o preço do caminhão novo não-poluidor e o preço do caminhão velho poluidor $k$, na época atual. Assinale-se que a literatura de economia do meio ambiente chama essa diferença de custos evitados ou de gastos defensivos (May, Lustosa e Vinha, 2003).

Por fim, sabendo que a frota tem $k$ caminhões, o custo ambiental por caminhão é expresso por:

$$
E_{p}=\frac{\sum E_{p}^{k}}{\sum k}
$$

A Equação (4) também pode ser escrita assim:

$$
E_{p}=\sum \frac{k_{I}}{K} \times E_{p}^{k, I}
$$

Onde $\sum \frac{k_{I}}{K}=1, k_{I}$ : é o número de caminhões com idade $I ; K$ : é o número total de caminhões e $E_{p}^{k, I}:$ é a externalidade ambiental referente aos veículos com idade $I$.

\footnotetext{
${ }^{1}$ Fonte: Souza e Clemente, 2009
} 


\subsection{Acidentes}

A literatura mensura o custo com acidentes através do conceito de rendimentos perdidos (Pindyck e Rubinfeld, 2005; IPEA, 2006). Os rendimentos perdidos equivalem à renda futura que a pessoa acidentada (inválida) ou falecida teria obtido caso o acidente não tivesse ocorrido.

Os rendimentos perdidos são aproximados pela seguinte expressão (Pindyck e Rubinfeld, 2005):

$$
V P\left(R P_{j}\right)=W_{0}^{J}-\frac{W_{0}^{J}(1+g)\left(1-\lambda_{1}\right)}{1+r}+\cdots+\frac{W_{0}^{J}(1+g)^{T}\left(1-\lambda_{T}\right)}{(1+r)^{T}}
$$

Onde $V P\left(R P_{j}\right)$ é o valor presente dos rendimentos perdidos do indivíduo $j ; W_{0}^{j}$ é rendimento do indivíduo $j$ no período do acidente; $g$ : é a taxa anual de crescimento do rendimento do indivíduo $j ; r$ é a taxa de desconto; $\lambda_{t}(t=1,2, \ldots, T)$ são as probabilidades de falecimento ou invalidez do individuo $j$ por outra causa.

A externalidade de custos de acidentes nas estradas $E_{A}$ por caminhão é dada na Equação (7).

$$
E_{A}=\frac{\sum V P\left(R P_{J}\right)}{\sum k}
$$

\subsection{Valor do frete}

Como foi dito anteriormente o frete não é considerado uma externalidade já que é um custo gerado que não se consegue recuperar por meio de impostos ou de penalidades ao agente que produz a externalidade. Porém a ineficiência gerada pela idade avançada da frota produz um custo para a sociedade que paga preços mais altos de frete e consequentemente nos produtos consumidos. Considerando isso, pode-se dizer que os caminhões velhos causam custos extras a sociedade, que passa a dispor de fretes relativamente mais altos. Sendo assim o frete será considerado neste artigo como uma pseudoexternalidade, pois gera custos a sociedade, mas são custos que não podem ser recuperados. 
Supõe-se que o valor do frete $\mathrm{C}$ pago pelo contratante do serviço de transporte do autônomo seja formado a partir dos custos, acrescentado da margem de lucro como pode ser visto na Equação (8) (Koutsoyiannis, 1979).

$$
C=(1+\mu) \times \operatorname{COM}_{t}
$$

Onde $\mu$ é o mark-up; COM: é o custo de operação, manutenção e de capital do caminhão por quilômetro percorrido cujo valor eleva-se à medida que o tempo passa $(\mathrm{t}=1,2, \ldots, \mathrm{T})$; porque esses custos sobem com o tempo.

O custo social relativo ao valor do frete é dado pela Equação (9).

$$
E_{F}=\frac{\sum\left(C^{k}-C_{M I N}\right)}{\sum k}
$$

Onde $E_{F}$ : é a externalidade de frete por caminhão; $C^{k}$ é o custo de operação, de manutenção e de capital do caminhão $k$ com idade maior do que a idade corresponde a de menor custo; $C_{M I N}$ é o custo mínimo de operação e manutenção e de capital de um veículo-tipo.

A Figura 1 mostra o comportamento do custo de operação e manutenção e do custo de capital ao longo do tempo de um equipamento qualquer. O ponto de custo mínimo, somatório dos custos de operação, manutenção e de capital, é denominado de vida útil econômica (Souza e Clemente, 2009; Valente et al, 1997).

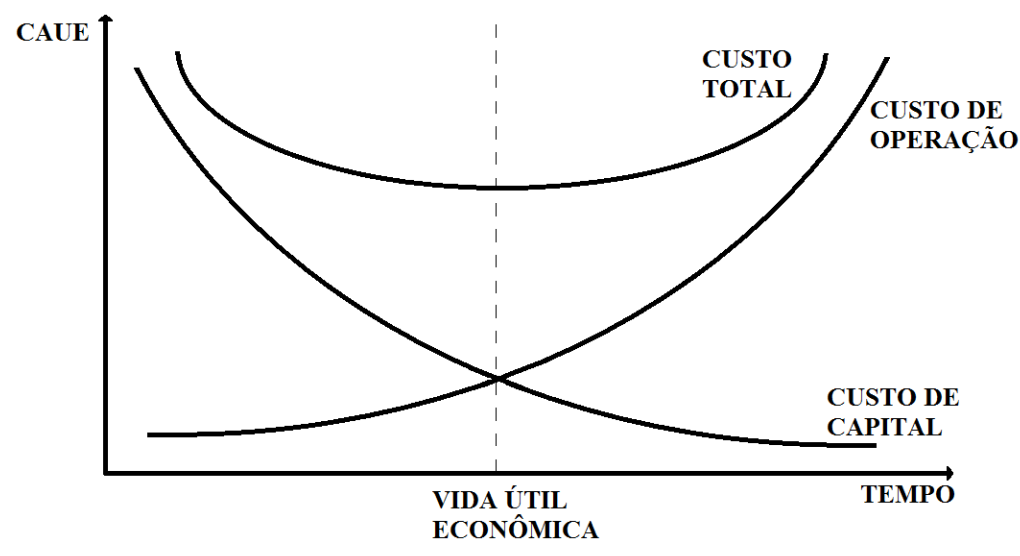

Figura 1 - Custo de capital, operação e de manutenção $x$ tempo $^{2}$.

\footnotetext{
${ }^{2}$ Fonte: Valente et al (1997).
} 


\section{Externalidades: análise empírica}

Com base na teoria apresentada é calculado o custo das externalidades somado-se ao custo do frete a partir de três mercadorias de relevância na agropecuária nacional: soja em grão, café em saca e boi em pé.

\subsection{Estudo de caso da soja: Mato Grosso - Porto de Santos (SP)}

A soja é cultivada principalmente nas regiões Centro-Oeste e Sul. Destaca-se o Mato Grosso e o Paraná, representando juntos 47,5\% da produção nacional, sendo que o Mato Grosso fica com a maior parte deste percentual. Entre 1990/1991 e 2004/2005, a área plantada com soja no Brasil cresceu 13,4 milhões de hectares, passando de 9,74 milhões de hectares para 23,18 milhões de hectares. A produção de soja do Estado Mato Grosso na safra 2007/2008 foi de 17,88 milhões de toneladas, volume 16,4\% acima da temporada anterior, sendo responsável por $30 \%$ da oleaginosa brasileira. Mesmo com problemas relacionados ao alto custo de produção e logística deficitária, os sojicultores estaduais ampliaram a área em 11,2\%, passando a 5,69 milhões de hectares (Fonte: MAPA, 2009). Devido a isto foi escolhido para o calculo a soja produzida no estado do Mato Grosso.

Atualmente a soja produzida no Mato Grosso é escoada até o porto de Santos através do modal rodoviário e também do modal ferroviário. Existe uma terceira opção de transporte pouco utilizada que é a hidroviária (Madeira) que também é ligada a malha ferroviária. A rota ferroviária é responsável pelo escoamento de cerca de $40 \%$ do milho e da soja produzida no Mato Grosso que chega até o porto de Santos, o restante é escoado por rodovias federais e estaduais, sendo as principais vias de escoamento a BR-364, a BR-154 e a BR-070, que liga o principal pólo de escoamento, Rondonópolis (terminal intermodal), localizado no sul do Mato Grosso a $202 \mathrm{~km}$ de Cuiabá até o Porto de Santos percorrendo $1.446 \mathrm{~km}$ no total. O caminhoneiro ao entrar no estado de São Paulo passa por 11 pedágios (Guia Quatro Rodas, 2010) até chegar ao destino, tendo um custo de $\mathrm{R} \$ 547,50$ por trecho (ida e volta), ou seja, um total de $\mathrm{R}$ \$ 1.095,50 só de pedágios.

Considerando a teoria e os dados acima, na análise empírica foi feito um cálculo comparativo entre um caminhão tipo transportador de soja com a idade média de 23 anos e outro na idade 
econômica, aferindo a diferença entre os custos de capital, operação e manutenção de ambos na rota estudada.

Para efeito de cálculo foi utilizada a rota da soja descrita anteriormente, cuja distância é de $1.446 \mathrm{~km}$ e que une o centro de produção de soja do Mato Grosso (região com maior concentração de fazendas produtoras e armazéns) até o Porto de Santos.

Segundo superintendente de Terminais da ALL, Carlos Eduardo Monteiro de Barros, a ferrovia da ALL que parte de Mato Grosso em direção ao porto de Santos (SP) deve conduzir este ano mais de 10 milhões de toneladas (equivalente a cerca de 40 por cento da safra matogrossense de soja e milho), volume este que passa antes pela BR-364. Ou seja, que 60\% da produção de soja do Mato Grosso vai pelas rodovias até o Porto de Santos passando pela BR364 como corredor principal de escoamento de caminhões graneleiros de soja.

Considerando uma densidade média da soja de 1,1 toneladas $/ \mathrm{m}^{3}$ e os caminhões graneleiros com uma capacidade média de $27 \mathrm{~m}^{3}$, um caminhão tipo graneleiro transporta 30 toneladas de soja aproximadamente. Portanto, para escoar 10,73 milhões de toneladas de soja $(60 \%$ dos 17,88 milhões de toneladas produzidas no Mato Grosso) são necessários 357.600 caminhões.

Supondo que cada caminhão consegue fazer duas viagens por safra, número razoável tendo em consideração o tempo de viagem total (velocidade média, quantidade de pedágios, qualidade das estradas, etc), tempo de parada para descanso do caminhoneiro, tempo de carga e descarga, tempo de volta do destino final ao ponto de origem, entre outros, precisa-se de 178.800 caminhões.

Por meio do Registro Nacional de Transportadores Rodoviários de Carga (RNTRC) (ANTT, 2009), 57,1\% desses caminhões são pertencentes aos transportadores autônomos, ou seja, 102.095 caminhões.

Pereira (2006) e Pereira e Rocha (2006) demonstraram que o custo de operação e manutenção de um caminhão no Brasil atinge seu ponto de mínimo com oito anos de idade, em média; ao custo de $\mathrm{R} \$ 0,76$ por $\mathrm{km}$.

Arruda (2010), com base nos dados de Pereira (2006) onde considerou o custo por quilometro para a idade de até 12 anos, estimou modelo por meio do Método dos Mínimos Quadrados 
Ordinário (Gujarati, 2006) para, a partir dele, encontrar o valor de custo de operação, manutenção e de capital de um caminhão com idade de 23 anos. O modelo de melhor ajuste aos dados é do tipo polinomial quadrática apresentado na Equação (10).

$$
C O M=\beta_{0}+\beta_{1} I+\beta_{2} I^{2}+\varepsilon
$$

Onde COM é o custo de capital, operação e manutenção do caminhão; $I$ : representa a idade média do caminhão; $\hat{\beta}_{0}, \hat{\beta}_{1}$ e $\hat{\beta}_{2}$ são os coeficientes 1,$141 ;-0,097$ e 0,0062 , respectivamente.

Com base na equação de Mínimos Quadrados e nos parâmetros estimados pode-se calcular:

$$
\text { COM }_{\text {Total }}=(\text { número de caminhões necessários }) \times(\text { rota } \mathrm{km}) \times(C O M / \mathrm{km})
$$

Os seguintes resultados foram obtidos para a frota autônoma com idade média igual 23 anos e idade média igual a 8 anos - idade econômica, segundo Pereira (2006):

$$
\begin{aligned}
& \mathrm{COM}_{\text {Total }}=\left(\text { frota atual }_{(t=23 \text { anos })}\right)=\mathrm{R} \$ 323,3 \text { milhões de reais } \\
& \mathrm{COM}_{\text {Total }}=\left(\text { frota atual }_{(t=8 \text { anos })}\right)=\mathrm{R} \$ 112,5 \text { milhões de reais }
\end{aligned}
$$

Portanto, o valor total da antieconomia é $\mathrm{R} \$ 210,8$ milhões por safra, um custo médio de $\mathrm{R} \$$ 2.065,17 por caminhão/ano.

Desconsiderando o valor do dinheiro no tempo, conforme foi calculado anteriormente, o montante perdido por trabalhar de forma antieconômica poderia ser aplicado na melhoria da infraestrutura existente. Por exemplo, na reforma dos postos de manobra, prédios das balanças, substituição dos trilhos das vias principais e na segregação das linhas, separando-as do tráfego rodoviário, recuperação do material rodante, otimização do layout de pátios e duplicação de linhas, aumento da capacidade de tração das locomotivas e extensão das ferrovias atuais. A renovação da frota de caminhões autônomos seria outra opção na qual poderia ser aplicada essa quantia, diminuindo assim os custos COM devidos ao envelhecimento da frota atual.

O custo médio por quilômetro construído de ferrovia é aproximadamente $\mathrm{R} \$ 2,5$ milhões e o custo de operação e manutenção médio é $\mathrm{R} \$ 90$ / 1000 tku. Considerando isso, se nada for 
feito para modificar a antieconomia anual atual de $\mathrm{R} \$ 210,8$ milhões, em um período de 18 anos, seria possível financiar a construção e a manutenção de uma nova ferrovia nesse trecho.

Para ter uma ideia do prejuízo, considerando a produção de soja na safra 2007-2008 no estado do Mato Grosso de 17,88 milhões de toneladas, e o preço da tonelada da soja na referida safra de $\mathrm{R} \$ 416,00$, o custo de capital, operação e manutenção da atual frota de caminhões autônomos representa o 2,83\% do valor total das vendas. Ou seja, aproximadamente 473.820 toneladas (7.897.000 sacas) que não tivessem sido vendidas.

Por outro lado, se a finalidade fosse reforçar a frota ferroviária atual com a compra de um comboio formado por duas locomotivas de tecnologia U23C da General Electric (GE) equipada com motor de $2.250 \mathrm{HP}$, custo aproximado de $\mathrm{R} \$ 4,5$ milhões cada, e com 30 vagões Hopper fechados, custo médio individual de $\mathrm{R} \$ 144.000$, some-se um custo total de $\mathrm{R}$ \$ 13,32 milhões que poderia ser financiado em menos de um mês.

No entanto, ao renovar a metade da frota autônoma de caminhões cuja idade média seja superior aos 15 anos (ou seja, renovar 103.217 caminhões) considerando que o preço do caminhão novo é de $\mathrm{R} \$ 180.000$ e o valor residual de $\mathrm{R} \$ 60.000,00$ o COM total atual seria reduzido à metade. Ainda considerando a antieconomia de R \$ 210,8 milhões anual, esse processo levaria 19 anos.

\subsection{Estudo de caso do café: Minas Gerais - Porto de Santos (SP)}

De acordo com relato de pesquisa no Centro do Comércio de Café de Minas Gerais (CCCMG, 2003), quase $90 \%$ do café produzido na região são direcionados às cooperativas (por seus cooperados), que se encarregam de armazenar e comercializar o café de acordo com as necessidades do produtor. Algumas cooperativas não compram o café, apenas se configuram como órgãos de apoio aos produtores, contudo, por serem o principal intermediário no processo de comercialização, podem influenciar fortemente o mercado. A MINASUL cobra uma taxa de $2,5 \%$ do valor final do café na hora da venda, apresentando-se com intermediadora de negócios e a COOXUPÉ normalmente compra o café dos produtores, caracterizando-se também como comerciante, torrefadora e exportadora.

A cooperativa COOXUPÉ é a melhor estruturada dentre as cooperativas, possui uma cadeia produtiva pouco complexa e é a única que comercializa café torrado e moído, sendo também a 
maior exportadora de café do Brasil com exportação própria, possuindo seu próprio padrão internacional de café e com filiais. Além de estar situada em vários pontos de Minas Gerais, concentrou-se também no porto de Santos.

A cooperativa MINASUL, localizada na cidade de Varginha possui uma cadeia produtiva bastante complexa, mas devido em grande parte à existência do Porto Seco, antiga estação Aduaneira do Interior (EADI), que é responsável por um grande escoamento de café para o exterior, gerando grandes volumes distribuídos no seu mercado, uma vez que não comercializa apenas presta serviços de entrepostagem, estufagem, e desembaraço aduaneiro.

De acordo com os processos logísticos de escoamento analisados na região produtora de Minas Gerais, especificamente pelas empresas citadas acima, os cafés adquiridos pelas cooperativas, são fornecidos pelos produtores desta e de outras regiões do estado. Após a transação comercial e vencimento do prazo de retirada do café da propriedade rural, os produtores levam-no até a cooperativa (para aqueles que possuem recurso próprio do frete) ou contratam uma transportadora para a coleta do café da propriedade rural e entrega do mesmo na cooperativa, podendo ser a Cooxupé ou a Minasul, como exemplos possíveis.

Após todo o processo na formação de padrões internacionais, o café é destinado à estufagem (carregamento do contêiner), feita nos armazéns gerais e em seguida é transportado para o Porto Seco de Varginha para o desembaraço aduaneiro pela Unidade local da Receita Federal. Normalmente, delimitado pelo importador, o café segue para os portos marítimos de Santos ou Rio de Janeiro, a critério do importador, o qual pagará o frete marítimo.

O café, quando entregue pelo produtor regional à Cooperativa Cooxupé, localizado em Guaxupé, aproximadamente 154,7 km de distância de Varginha, onde situa-se a MINASUL, sua concorrente, passa por outros canais de distribuição para chegar aos portos marítimos. Estes canais não são de intermediários e sim da própria Cooxupé. O café negociado pela Cooxupé, após feitas as análises e conferência das amostras, é transportado pelo produtor ou pela cooperativa ou por uma empresa de transporte terceirizada ou mesmo transportadores autônomos. A cooperativa MINASUL normalmente rebeneficia e armazena o café para a comercialização para o produtor dono do café, portanto há uma grande diferença entre as duas empresas. 
Essa diferença acontece na comercialização da Cooperativa Cooxupé para si mesma e para os produtores, ou seja, além de rebeneficiar e comercializar o café para o produtor, esta cooperativa compra parte dos cafés que tem em seus estoques, industrializa-os, distribui em suas lojas varejistas e os comercializa tanto no mercado doméstico quanto no exterior, caracterizando-se como empresa exportadora. A COOXUPÉ é a cooperativa de maior destaque no país, distanciando-se das demais pela sua superioridade no rebeneficiamento do café mineiro e brasileiro. Na própria estrutura da COOXUPÉ, o café é estufado e transportado para os portos marítimos de Santos ou Rio de Janeiro, a cooperativa possui uma unidade no Porto de Santos, e por lá segue a maior parte de fluxo desse produto comercializado.

Como a COOXUPÉ possui uma filial no porto de Santos, tornou-se mais atrativo fazer a estufagem em Guaxupé, e o desembaraço aduaneiro em Santos, minimizando mais ainda os processos e planejamentos de contêiner para desembaraço no despachante aduaneiro em Guaxupé. Verifica-se que as cooperativas de produtores de café se tornaram grandes detentoras da produção e comercialização do café de Minas, exercendo grande poder de barganha no mercado do café, pois elas são responsáveis por comercializar mais de $90 \%$ do café produzido na região.

Os cafés adquiridos são de todas as microrregiões do sul, oeste e, em parte, do norte de Minas Gerais. Geralmente, a cooperativa adquire café de regiões com aproximadamente $1.000 \mathrm{~km}$ de distância e destina seu produto ao próprio estado de Minas para as exportadoras dessa região. Normalmente são entregues nas exportadoras situadas em Varginha, pólo comercial regional do mercado dos cafeicultores de Minas Gerais, ou em Guaxupé na cooperativa Minasul.

O custo médio por contêiner transportando $21.600 \mathrm{~kg}$ ou 360 sacas de café desde Varginha até o Porto de Santos é de $\mathrm{R} \$ 1.500$. Esse valor dividido pelas 360 sacas a granel ilustra o custo de $\mathrm{R} \$ 4,17$ por saca de café, que em negociação pode cair para $\mathrm{R} \$ 3,5$ por saca, conforme a empresa transportadora que faça o serviço. O percurso mais frequentado pela transportadora para exportação de café são nas rotas de saída de Varginha com destino a Santos, Rio de Janeiro e Guarujá, nos portos marítimos. Os canais de distribuição normalmente são delimitados pelos caminhos mais curtos, o que nem sempre é o melhor caminho, podendo ter interferências de pedágios, más condições de tráfego pelo fluxo de carros ou caminhões ou, ainda, por deficiência da estrada, como buracos ou outras irregularidades que podem atrasar no percurso. 
O porto seco de Varginha possui menos filas, o que reduz o tempo de espera para carregamento ou descarregamento da carga, dotando assim ao sistema de uma maior rapidez no fluxo logístico de transporte. Este fator está diminuindo os riscos do transportador ter que esperar um dia a mais no porto marítimo, deixando de concluir outros fretes, correndo riscos desnecessários.

Custo de frete "Guaxupé via Varginha" seguindo para Santos acresce uma distância aproximada de 154,7 km de percurso, com uma duração de aproximadamente 2 horas. Portanto, aumenta-se assim o consumo de combustível, levando a considerar esse possível percurso inviável.

Tabela 2. Resumo Guaxupé - Varginha - Santos ${ }^{3}$.

\begin{tabular}{cccc}
\hline Origem & Guaxupé & Guaxupé & Varginha \\
\hline Passando por & Varginha & - & - \\
Destino & Santos & Santos & Santos \\
Distância percorrida & $515,7 \mathrm{~km}$ & $355,7 \mathrm{~km}$ & $361,0 \mathrm{~km}$ \\
Tempo do percurso & $7 \mathrm{~h} 07 \mathrm{~min}$ & $4 \mathrm{~h} 12 \mathrm{~min}$ & $4 \mathrm{~h} 55 \mathrm{~min}$ \\
Velocidade média & $72,3 \mathrm{~km} / \mathrm{h}$ & $84,6 \mathrm{~km} / \mathrm{h}$ & $73,4 \mathrm{~km} / \mathrm{h}$ \\
\hline
\end{tabular}

Santos lidera nas embarcações de cafés para exportação mesmo o porto do Rio de Janeiro sendo forte concorrente. Hoje toda a produção do café do sul de Minas Gerais é levada pelo modal rodoviário para os portos de Santos e Rio de Janeiro, sendo o principal destino das exportações de café a Alemanha. O modal ferroviário não é utilizado nesse escoamento devido a problemas técnicos e operacionais nos terminais intermodais.

O Porto de Santos registrou um crescimento de 2,3\% nas exportações de café durante o ano safra 2009/2010 (que teve início em julho do último ano e terminou no mês passado), em relação ao mesmo período de 2008/2009. No total, foram embarcadas 22,2 milhões de sacas de 60 quilos. Já no exercício anterior foram 21,7 milhões de sacas. Os dados integram o balanço divulgado pelo Conselho dos Exportadores de Café do Brasil (Cecafé).

\footnotetext{
${ }^{3}$ Fonte: CCCMG, 2010.
} 
O café é transportado apenas pelo contêiner de 20' (pés), pois é caracterizado como uma carga pesada e, caso houvesse a intenção de utilizar o contêiner de 40' (pés), o mesmo não poderia estar cheio por não suportar o peso e quebrar. Portanto, para uma carga com peso de $21.600 \mathrm{~kg}$ líquido, como se faz nos contêineres de 20', no contêiner maior ficaria um espaço ocioso, o que pagaria um custo maior pelo aluguel e maior custo também com o aluguel de espaço no navio para exportação. A diferença é que o contêiner de 20 ' suporta um peso determinado que pode ser suspendo pelos guindastes em sua lotação. O contêiner de 40' não pode ser carregado de mercadorias pesadas, então, é usualmente preciso no transporte de eletrônicos que fazem maior volume e seu peso não altera muito mais que o peso de um contêiner de 20' que, pelo volume não caberia nesta unidade. A totalidade de produtos que passa pelo porto seco de Varginha é transportada em contêiner devido à política de garantia e segurança do produto.

Tendo em consideração que as duas maiores cooperativas de café de Minas Gerais encontramse localizadas nas cidades de Guaxupé e Varginha, conforme foi aprofundado anteriormente, cujas distâncias até o Porto de Santos são de $355,7 \mathrm{~km}$ e $361,0 \mathrm{~km}$ respectivamente, e desconhecendo qual proporção da produção atende cada uma por falta de informação fidedigna, utilizaremos no cálculo uma distância média desde a cooperativa até o porto de Santos de $358,35 \mathrm{~km}$.

Por outro lado, teremos uma distância adicional que vai compor a distância total do frete. A mesma é a média geométrica das distâncias entre as áreas cultivadas de café comentadas anteriormente (Sul e Centro Oeste; 120 km, Cerrado Mineiro; 355 km e a Zona da Mata; 760 $\mathrm{km}$ ) e o ponto médio entre a cidade de Varginha e Guaxupé. Não foi calculado através de uma média ponderada com as áreas cultivadas devido ao desconhecimento da porcentagem das respectivas produções que foram para exportação e quais delas destinadas ao mercado interno. A distância média obtida foi de $318,72 \mathrm{~km}$. Então a distância total do frete considerada no cálculo foi de $677,07 \mathrm{~km}$ (média geométrica entre as áreas cultivadas e as duas cooperativas representativas da região mais distância média entre as cooperativas e o porto de Santos, ou seja, 358,35 km +318,72 km). O resumo das distâncias pode ser observado na Tabela 2 .

Considerando uma produtividade média por hectares de 22,5 sacas/ha teremos uma produção total de 23,82 milhões de sacas, e supondo que aproximadamente $80 \%$ da mesma seja 
exportada, teremos 19,06 milhões de sacas que deverão ser transportadas até o Porto de Santos (ponto de destino).

Sabendo que a capacidade de um caminhão transportador de café pode levar no máximo 360 sacas, pelo motivo comentado anteriormente, serão necessários 52.941 caminhões. Supondo que cada caminhão faz três viagens durante a safra, teremos 17.647 caminhões. Através do relatório feito pela ANTT do ano 2009 a respeito do panorama do Registro Nacional de Transportadores Rodoviários de Carga (RNTRC), podemos dizer que 57,1\% desses caminhões seriam pertencentes aos transportadores autônomos, portanto seriam 10.076 caminhões.

Utilizando a equação polinomial para o cálculo do custo de capital, operação e manutenção (COM) por quilômetro por caminhão (Arruda, 2010), teríamos que um caminhão na idade média atual da frota autônoma (22,82 anos segundo relatório da ANTT) teria um custo COM de R 2,063/km, e o custo COM na idade econômica (8 anos segundo Arruda, 2010) é de R\$ 0,7286/km. Com base nos dados acima e utilizando a seguinte equação:

$$
\operatorname{COM}_{\text {Total }}=\left[n^{\circ} \text { caminhões necessários }\right] \times[\operatorname{rota}(\mathrm{km})] \times\left[\frac{\mathrm{COM}}{\mathrm{km}}\right]
$$

Teríamos os seguintes resultados:

$$
\begin{gathered}
C O M_{\text {Total }}(\text { frota atual na idade média })=R \$ 14,07 \text { milhões de reais } \\
C O M_{\text {Total }}(\text { frota atual na idade econômica })=R \$ 4,97 \text { milhões de reais }
\end{gathered}
$$

Portanto, o valor total que está se deixando de economizar é R \$9,1 milhões por safra do café, representando um custo médio de $\mathrm{R} \$ 903,48$ por caminhão/ano. Considerando o preço médio por saca de $\mathrm{R} \$ 261,69$ (valor obtido da safra 2009), essa perda representa 3,48 milhões de sacas, ou seja, o equivalente a 9.661 viagens a menos.

\subsection{Estudo de caso do boi em pé: Pará - Porto de Vila do Conde}

As exportações de bovinos em pé na cidade de Belém foi uma novidade da qual não demorou a descobrir: filas enormes de carretas boiadeiras começaram a se formar na Avenida Visconde de Souza Franco, conhecida por Doca, reduto nobre que abriga bares e restaurantes e onde a 
elite costumava se reunir. Quando o primeiro navio-gaiola partiu, deixou um rastro de fezes que chamou a atenção do Ministério Público. O embarque das boiadas foi então transferido para o Porto de Vila do Conde, do outro lado da baía do Guajará, antes utilizado apenas pelas empresas exportadoras de alumínio e minérios.

No porto de Belém está proibido o embarque de boi vivo por questões ambientais, ficando viável a venda de bovinos vivos apenas pelo porto de Vila do Conde, em Barcarena, a 40 quilômetros de Belém. Outro fator que onerou a venda foi à criação da taxa do Certificado de Embarque de Bovídeos para o Exterior pela Lei 7.076, de 27 de dezembro de 2007 (Brasil, 2007), que fixou o pagamento de aproximadamente $\mathrm{R} \$ 23,00$ por cabeça exportada.

A saga amazônica acontece no Porto de Vila do Conde, próximo a Belém, onde os naviosgaiolas (de bandeiras europeias) preparam-se para o embarque de 12 mil bois vivos que viajam em pé até o Porto de Beirute, no Líbano, após ter viajado pelas estradas paraense por mais de mil quilômetros. A primeira viagem de boi desde o Pará até o Líbano chegavam a durar 20 dias.

Geralmente a rota do boi começa na fazenda onde é criado o boi, passando por várias fazendas da zona até completar o caminhão, e logo depois faz uma escala no centro de confinamento de outra fazenda no caminho ao porto, para "desestressar" o gado antes de subir aos navios no Porto de Vila do Conde, e terminaria no Líbano, 12 dias depois. Na Venezuela os bovinos são comprados por frigoríficos. A maior concentração de fazendas criadoras de gado está no sudoeste e sudeste do estado.

Antes de ser embarcado, os responsáveis e encarregados das cabeças de gado, sobe no navio para fazer uma vistoria completa dos alojamentos bovinos. Verifica a qualidade da água e o estoque de feno e ração preparado para a viagem. A primeira tarefa do pessoal é pegar os medicamentos e o laço para vistoriar o gado distribuído em baias nos 14 deques do navio. Numa viagem ao Líbano, a perda pode chegar a $2 \%$ dos animais embarcados. Para a Venezuela, viagem que dura de três a quatro dias, não há registro de óbitos. O que dá mais trabalho aos encarregados é reagrupar os animais nas baias, pois os maiores tomam conta dos coxos e não deixam os menores chegarem perto. É o trabalho que chamam de "padronização da boiada". 
Como a maioria desses animais é criado solto no pasto, é preciso habituá-los ao ambiente de confinamento no navio. Ao mesmo tempo, como sempre perdem peso nas longas viagens pelas estradas do Pará e do Maranhão até chegar ao destino final, os bois recebem uma alimentação reforçada de feno e ração, a mesma que terão no navio, cerca de 18 quilos por dia.

O comprimento da carreta que transporta os bois desde a fazenda até o porto tem um comprimento de 23 metros, e carrega entre 30 a 40 bois de 600 quilos em média, dependendo da marca e modelo do caminhão. O trabalho de apartar os bois não é nada fácil em razão de uma exigência dos importadores libaneses. Como eles não aceitam animais castrados, só viajam bois inteiros - os touros.

Tendo em consideração que a região sudoeste e sudeste são as regiões de maior produção e criação de boi do estado, consideramos a origem do percurso na cidade chamada Novo Progresso, localizada no centro sul do estado, e até o Porto de Vila do Conde, são aproximadamente $1.000 \mathrm{~km}$ em linha reta. Mas devido à falta de infraestrutura rodoviária na região amazônica, péssimas condições das estradas existentes e restrições da própria natureza, o percurso total é de aproximadamente $1.550 \mathrm{~km}$, levando entre dois a três dias para chegar ao porto em questão, e tendo filas na chegada aguardando o embarque. Os principais trechos do percurso são da BR - 163, BR - 230 e PA - 475, tendo aproximadamente $800 \mathrm{~km}$ sobre caminhos de terra batida em condições regulares.

A respeito das exportações do primeiro semestre de 2010, já foram enviadas para a Venezuela, Líbano, Egito e alguns países africanos, 291 mil cabeças, com um faturamento de US\$ 270 milhões, sendo um volume 24\% superior aos embarques do primeiro semestre de 2009, quando o setor faturou US\$ 183 milhões, com a venda de 236 mil cabeças para o exterior.

De acordo com Alex Silva, da Scot Consultoria (USDA apud MAPA 2009), aponta um crescimento de $15 \%$ do setor brasileiro em 2010, mas estimativas da consultoria apontam para um volume de 620 mil cabeças de bovino vivo exportados até o fim do ano. No ano passado foram embarcados, especialmente via Pará, 519 mil cabeças. Tendo um perfil conservador e não tão otimista, no cálculo consideraremos 582.000 cabeças de boi em pé como exportações 
totais. Segundo Alex Silva, os preços médios praticados em 2009 giraram em torno de US\$ 786 por cabeça. Este ano, a cabeça de boi em pé valorizou em média $18 \%$.

Considerando uma capacidade média do caminhão transportador de gado (caminhão gaiola) de 35 bois em pé, e tomando como hipótese que cada caminhão faz só uma viagem durante o período de exportação, número razoável tendo em consideração o tempo de viagem total (velocidade média, quantidade de pedágios, qualidade das estradas, etc), tempo de parada para descanso do caminhoneiro e do gado, tempo de carga e descarga, tempo de volta do destino final ao ponto de origem, entre outros; precisaríamos de 16.629 caminhões transportadores.

Através do RNTRC (2009), podemos dizer que 57,1\% desses caminhões seriam pertencentes aos transportadores autônomos, ou seja, 9.495 caminhões.

Utilizando a equação polinomial para o cálculo do custo de capital, operação e manutenção (COM) por quilômetro por caminhão (Arruda, 2010), teríamos que um caminhão na idade média atual da frota autônoma de 22,82 anos segundo RNTRC (2009) teria um custo COM de $\mathrm{R} \$$ 2,063/km, e o custo COM na idade econômica (8 anos segundo Arruda, 2010) é de R\$ $0,7286 / \mathrm{km}$.

Com base nos dados acima e utilizando a seguinte equação:

$$
\operatorname{COM}_{\text {Total }}=\left[n^{\circ} \text { caminhões necessários }\right] \times[\operatorname{rota}(\mathrm{km})] \times\left[\frac{\mathrm{COM}}{\mathrm{km}}\right]
$$

Teríamos os seguintes resultados:

$$
\begin{aligned}
& C O M_{\text {Total }}(\text { frota atual na idade média })=\mathrm{R} \$ 30,36 \text { milhões } \\
& C O M_{\text {Total }}(\text { frota atual na idade média })=\mathrm{R} \$ 10,72 \text { milhões }
\end{aligned}
$$

Portanto, o valor total que está se deixando de economizar é R \$ 19,6 milhões por ano, o que representa um custo médio de $\mathrm{R} \$ 2.068,32$ por caminhão/ano. Considerando o preço médio por cabeça de R\$1.399 (valor médio obtido das exportações 2009), essa perda representa quase $2,5 \%$ das vendas totais do estado, ou seja, mais de 14 mil cabeças de boi ou o equivalente a 400 viagens a menos. 


\subsection{Poluição atmosférica}

Assume-se que o preço do caminhão novo, em 2009, com tecnologia embarcada antipoluição atmosférica seja de $\mathrm{R} \$ 153.438,00$ e que o caminhão velho, com vinte e três anos de idade ( $T$, na equação 3), fora vendido ou comprado por $\mathrm{R} \$ 65.251,00 \mathrm{em} 1987$. O valor atualizado do caminhão velho para 2009 é de R $\$ 171.848,43$, a taxa $\delta=4,5 \%$ ao ano. Agora, da aplicação da Equação (2) e, depois, da Equação (1), tem-se que $E_{P}$ é igual a $\mathrm{R} \$ 153.438,00$ por caminhão.

Usando a fórmula de anualização, Equação (20) abaixo, (Brigham e Houston, 1999; Bruni e Famá, 2008; Souza e Clemente, 2009), pode-se obter o valor da externalidade por caminhão/ano igual a $\mathrm{R} \$ 23.262,68$.

$$
E_{P}^{A}=\frac{\delta \times(1+\delta)^{N}}{(1+\delta)^{N}-1}
$$

Onde $E_{P}^{A}$ : é a externalidade poluição atmosférica anualizada; $E_{P}$ : é igual a $\mathrm{R} \$ 153.438,00 ; \delta$ é igual a 4,5\% ao ano; $N$ é igual a 8 anos; é a idade relativa a vida econômica de um caminhãotipo, conforme Pereira (2006) e Pereira e Rocha (2006).

\subsection{Acidentes}

O IPEA (2006) estima que a maioria dos acidentes nas estradas é causado por caminhões velhos e que os custos anuais com esses acidentes atingem R\$ 3 bilhões, isto é, que $\sum V P\left(R P_{j}\right) \cong \mathrm{R} \$ 3,0$ bilhões, na equação (6). Estão incluídos nesse valor os custos com seguridade social por invalidez precoce e os relativos aos rendimentos perdidos.

Sabendo que a atual frota brasileira de caminhões é de 1,4 milhão, então, o custo unitário aproximado com acidentes envolvendo caminhão é de R \$ 2,2 mil por ano. Cabe ressaltar que se fossem considerados apenas os caminhões velhos esse custo seria ainda mais elevado. 


\section{Análise de resultados}

Sabendo que a idade econômica de um caminhão é de oito anos, e que a partir dessa idade a frota começa a operar de forma antieconômica trazendo prejuízo; foi observado que com a frota atual envelhecida (23 anos) o custo de capital, operação e manutenção (COM) se torna em média quase três vezes maior do que se a frota estivesse em idade econômica.

Para o estudo de caso apresentado da soja, segundo os cálculos são necessários 102.095 caminhões autônomos para o escoamento da safra e supondo que cada caminhão faz duas viagens de $1.446 \mathrm{~km}$ durante a safra, é possível concluir que se houvesse uma frota renovada deixaria de ser gasto anualmente um valor de $\mathrm{R} \$ 210,8$ milhões. Portanto representa um custo médio de $\mathrm{R} \$ 2.065,17$ por caminhão/ano.

No caso do café mineiro, para o escoamento dessa mercadoria agrícola desde Minas Gerais até o Porto de Santos em São Paulo, percurso de aproximadamente 677,1 km conforme os cálculos, foram estimados que fossem necessários 10.076 caminhões autônomos, e supondo que cada autônomo faz três viagens durante a safra em questão; consequentemente devido à frota envelhecida ter-se-ia uma antieconomia de $\mathrm{R} \$ 9,1$ milhões, representando uma externalidade de $\mathrm{R} \$ 903,48$ por caminhão/ano.

A respeito do frete do boi em pé, o percurso tem aproximadamente $1.550 \mathrm{~km}$ levando os animais desde o sudoeste do Pará até o Porto Vila do Conde perto de Belém, precisando assim de 10.115 caminhões autônomos para o transporte desses animais e supondo que cada caminhão faz só uma viagem devido às condições das estradas, distâncias, tempo da viagem, roteiro de alto risco, além de outras variáveis consideradas; tem-se então um gasto anual de R \$ 20,9 milhões. Pode se observar então que devido à elevada idade média da frota que oferece o serviço do frete um custo médio anual de $\mathrm{R} \$ 2.068,32$ por caminhão/ano. 
Tabela 3 - Resumo esquemático dos cálculos feitos ${ }^{4}$.

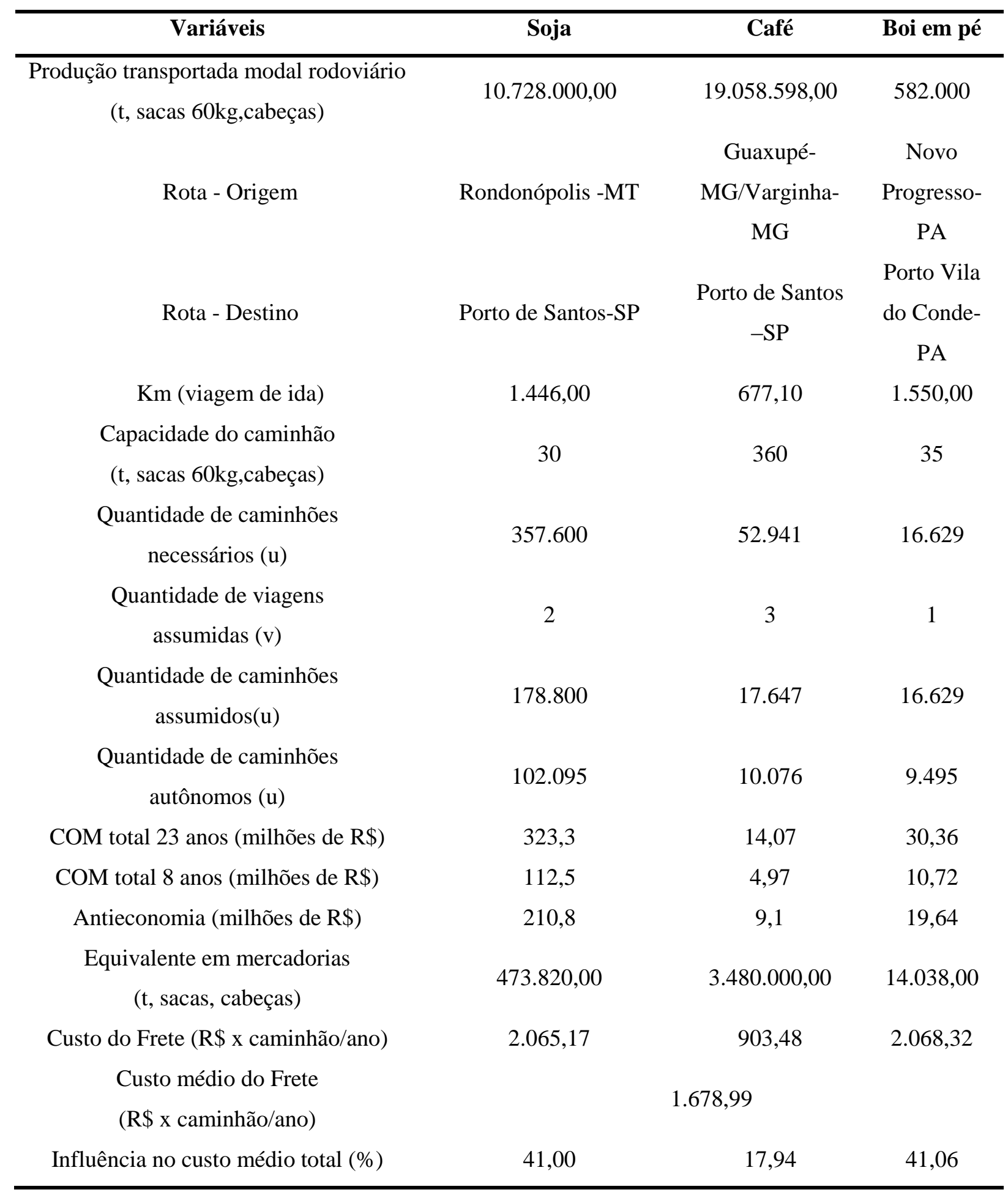

\footnotetext{
${ }^{4}$ Fonte: Elaboração própria.
} 
A partir dos custos médios obtidos segundo cada mercadoria, pode-se calcular um custo médio geral do frete aplicando uma média aritmética, como pode ser observado na Tabela 3, tem-se uma externalidade negativa média no valor do frete de $\mathrm{R} \$ 1.678,99$ por caminhão/ano e uma antieconomia total somando esses três produtos de $\mathrm{R} \$ 240,8$ milhões. A participação de cada mercadoria nesse custo social médio é: $41,0 \%$ da soja causado pela imensa produção de soja no Mato Grosso, 41,06\% do boi em pé gerado pela grande distância percorrida pelo transportador e 17,94\% do café tendo uma produção e distância intermediárias se formos comparar com os outros dois produtos agropecuários analisados.

É importante esclarecer que os cálculos foram efetuados supondo que o caminhão do transportador autônomo somente realiza determinada quantidade de viagens ao ano, no caso da soja percorrendo durante a safra um total de $5.784 \mathrm{~km}$ (duas viagens de $2.892 \mathrm{~km}$ ), no caso do café percorrendo 4.062,6 km (três viagens de 1.354,2 km) e no caso do boi percorrendo $3.100 \mathrm{~km}$ (uma viagem de $1.550 \mathrm{~km}$ ), quando na realidade o mesmo caminhoneiro autônomo geralmente participa das safras de outros produtos agropecuários ao longo do ano.

Conforme os cálculos efetuados, a somatória dos custos subjacente à frota autônoma de caminhões gera um custo para a sociedade de pelo menos $\mathrm{R} \$ 27.141,67$ por caminhão/ano, como pode ser observado na Tabela 4 . Esse custo corresponde a $15 \%$ do preço de um caminhão novo não-poluidor com tecnologia embarcada.

Tabela 4 - Custo social total anual por caminhão, em reais ${ }^{5}$.

Custo do Frete Custo com Acidentes Custo Ambiental Custo Total

\begin{tabular}{llll}
\hline $1.678,99$ & $2.220,00$ & $23.262,68$ & $27.141,67$ \\
\hline
\end{tabular}

Cabe ressaltar que nessa aproximação faltam os custos dos congestionamentos, e que os caminhoneiros autônomos percorrem um números de viagens determinado participando de uma única safra, quando na realidade participam das safras de várias mercadorias durante o ano, ou seja que pode-se atingir valores bem superiores dos obtidos.

\footnotetext{
${ }^{5}$ Fonte: elaboração própria.
} 


\section{Conclusão}

Este trabalho apresentou em termos aproximados os custos sociais provocados pela atual frota brasileira autônoma de caminhões da agropecuária nacional. A ênfase foi na mensuração dos custos sociais do valor do frete cobrado, das externalidades ambientais, particularmente, a poluição do ar, e das externalidades de acidentes nas estradas com vítimas fatais. Para o cálculo foi utilizado três casos da agropecuária nacional primeiro caso da soja em grão, segundo da saca de café e terceiro do boi em pé. Esses casos foram escolhidos devido a importância na agropecuária e também devido a utilização de três tipo de caminhões diferentes: graneleiro, carga geral e gaiola(carga viva), respectivamente. Em cada caso foi estimado o centro geográfico da região produtora de cada mercadoria e a distância percorrida até os respectivos portos para exportação.

Cabe ressaltar que o presente trabalho não considerou o custo com congestionamentos devido a dificuldade de mensuração do mesmo, outra restrição do trabalho é ter considerado somente a vida dos caminhoneiros como forma de mensuração dos acidentes, não levando em conta outros indivíduos envolvidos nos acidente. Lembra-se que os custos ambientais considerados foram medidos de acordo com o método de custos evitados, caso quisesse medir o custo de reparar os danos provocados pela frota antiga é provável que os custo encontrados seriam bem superiores. Além de outras externalidades que por limitações de tempo e dificuldade de obtenção de dados não foram considerados para o cálculo, tais como, custo de congestionamento, danos provocados ao patrimônio pelos acidentes de trânsito, poluição (não só a atmosférica), entre outros.

Reconhecendo que a atual frota brasileira de caminhões provoca perdas excessivas ao bemestar da coletividade devido ao envelhecimento da mesma e conhecida é sua relevância para a atividade agropecuária nacional parece razoável abordar a renovação da frota como prioridade de governo e com políticas públicas e programas de renovação da frota mais atrativos e eficientes. Segundo o cálculo efetuado no trabalho chegamos ao valor aproximado da externalidade de R $27.141,67$ por caminhão por ano. Considerando as dificuldades enfrentadas no cálculo afirma-se que o valor pode estar subestimado.

O governo atual do Brasil não tem negligenciado a renovação da frota de caminhões; tanto é que lançou o programa MODERCARGA-BNDES, em 2004, para caminhoneiros autônomos. 
O mesmo não logrou sucesso; as principais razões para o seu insucesso foram: (a) o alto custo do dinheiro; e (b) as elevadas exigências de garantias conversíveis em dinheiro que assegurassem a liquidação do empréstimo. No ano 2009, o governo lançou o programa PROCAMINHONEIROS, com os mesmos vícios do programa anterior. Arruda (2010) mostrou que os caminhoneiros autônomos não auferem renda do trabalho suficiente para servir uma dívida para trocar o seu caminhão.

Finalmente, o problema que enfrentamos ao lidar com ações que geram efeitos negativos não se limitam a restringir os responsáveis; é preciso decidir se os ganhos provenientes da prevenção desses efeitos negativos são maiores ou menores que as perdas sofridas pelo resultado do término da ação que produzia o efeito, portanto resulta fundamental precificá-los.

\section{Referências}

Agência Nacional de Transporte Terrestre - ANTT (2009) Dados do RNTRC. Disponível em www.antt.gov.br.

Arruda, B. D. L. (2010) Análise dos programas nacionais de financiamento para renovação de frota dos transportadores autônomos. Dissertação (Mestrado em Transportes) - Universidade de Brasília, Brasília.

Bruni, A. L. e Famá, R. (2008) Matemática financeira. São Paulo: Editora Atlas.

Buarque, C. (1984) Avaliação econômica de projetos. Rio de Janeiro: Editora Campus.

Castro, N. (2012) Mensuração de externalidades do transporte de carga brasileiro. Journal of Transport Literature, vol. 7, n.1, pp. 163-181.

Centro do Comércio do Café de Minas Gerais - CCCMG (2003) Relatório da atividade. Disponível em www.cccmg.com.br.

Confederação Nacional do Transporte - CNT (2009) Boletim Estatístico CNT.

Contador, C. R. (2000) Projetos sociais: avaliação e prática: impacto ambiental, externalidades, benefícios e custos sociais. São Paulo: Atlas.

Cruvinel, R. R. S., Pinto, P. V. H. e Granemann, S. R. (2012) Mensuração econômica da emissão de $\mathrm{CO} 2$ da frota dos transportadores autônomos de cargas brasileiros. Journal of Transport Literature, vol. 6, n. 2, pp. 234-252.

Gujarati, D. (2006) Econometria básica. Rio de Janeiro: Campus.

Instituto de Pesquisa Econômica Aplicada - IPEA. (2006) Impactos sociais e econômicos dos acidentes de trânsito nas rodovias brasileiras - Relatório Executivo. Brasília, IPEA/DENATRAN/ANTP.

Koutsoyiannis, A. (1979) Modern microeconomics. Macmillan, London.

May, P. H., Lustosa, M. C. e Vinha, V. (2003) Economia do meio ambiente: teoria e prática. Rio de Janeiro: Campus. 
Meyer, C. R. (2001) Implicações energético-ambientais de esquemas de sucateamento de automóveis no Brasil. Dissertação (Mestrado) - Departamento de Ciências em Planejamento Energético, Universidade Federal do Rio de Janeiro, Rio de Janeiro.

Ministério da Agricultura, Pecuária e Abastecimento - MAPA (2007) Cadeia produtiva da soja. Secretaria de Política Agrícola, Instituto Interamericano de Cooperação para a Agricultura. Coordenador Luiz Antonio Pinazza. IICA: MAPA, Brasília.

Ministério da Agricultura, Pecuária e Abastecimento - MAPA (2009) Projeções do agronegócio Brasil - 2008/09 a 2018/19. Brasília: AGE- Assessoria de Gestão Estratégica.

Pereira, D. B. S. (2006). Análise do impacto das condições de rodovias pavimentadas na renovação da frota de transporte rodoviário de carga. Dissertação (Mestrado em Transportes) - Faculdade de Tecnologia, Universidade de Brasília, Brasília.

Pigou, A. C. (1932) The economics of welfare. London: Macmillan.

Pindyck, R. S. e Rubinfeld, D. L. (2005) Microeconomia. São Paulo: Makron.

Rocha, C. H. e Faria, J. R. (2010) Financiamento público da renovação da frota brasileira autônoma de caminhões. Boletim de Economia \& Tecnologia, vol. 23, ano 6, p. 125-137.

Rocha, C. H., Arruda, B. D. L. e Rocha, M. O. M. (2009) Renovação da frota de caminhões de carga agropecuária. XXIII Congresso de Pesquisa e Ensino em Transportes, Vitória

Rocha, C. H., Ronchi, R. C. Moura, G.A. (2011) Custos externos subjacentes à atual frota autônoma de caminhões do Brasil: um estudo empírico. Revista ANTT, vol. 3, n. 1.

Sandoval, D. M. G. L., Ronchi, R. D. G. e Rocha, C. H. (2010). Custos sociais provocados pela atual frota brasileira autônoma de caminhões. XXIV Congresso de Pesquisa e Ensino em Transportes, ANPET, Salvador.

Souza, A. e Clemente, A. (2009) Decisões financeiras e análise de investimentos. São Paulo: Atlas.

Souza, A. e Clemente, A. (1997) Decisões financeiras e analise de investimentos: fundamentos, técnicas e aplicações. São Paulo: Atlas.

Valente, A. M., Novaes, A. G., Passaglia, E. e Vieira, H. (1997) Gerenciamento de transporte e frotas. São Paulo: Thomson Learning. 